\title{
CHEMOPREVENTIVE EFFECT OF GREEN TEA AND CURCUMIN IN INDUCED ORAL SQUAMOUS CELL CARCINOMA: AN EXPERIMENTAL STUDY
}

\author{
Mai M. Saleh ${ }^{1 *} M S c$, Zeinab E. Darwish ${ }^{2} P h D$, Manal I. El Nouaem²$P h D$, Ghada M. Mourad ${ }^{3}$ \\ $P h D$, Omneya R. Ramadan ${ }^{4} h D$
}

\begin{abstract}
INTRODUCTION: Oral squamous cell carcinoma (OSCC) has the highest mortality rates among all carcinomas and is the most common head and neck cancer. Several natural compounds and micronutrients have been under investigation for their efficacy in head and neck cancer chemoprevention. Green tea contains various cancer preventive catechins that have a role in preventing cancer recurrence in various organs in humans. Curcumin, a natural polyphenol, is one of the most investigated biomolecules from Mother Nature. Curcumin has been shown to exert significant growth inhibitory effect on oral precancerous and carcinoma cell lines, and the effect is synergistic with epigallocatechin gallate, the most abundant polyphenol in tea.

OBJECTIVES: To assess the chemopreventive effects of green tea and curcumin through induction of hamster buccal pouch carcinoma by using an apoptotic marker and compare their effect each alone and in combination.

MATERIALS AND METHODS: Squamous cell carcinoma was chemically induced in fifty Syrian golden hamsters divided into 5 groups (10 each). The first group was used as normal control group. The second group received the carcinogenic agent only. The other three groups received green tea, curcumin and combination of both, respectively.

RESULTS: Normal control group (A) revealed neither pathological nor inflammatory changes in the buccal pouch with $1.72 \%$ of the cells underwent apoptosis while the cells of positive control group (B) resulted in $11.57 \%$ apoptosis. In the study groups, treatment of the cells with green tea (C), curcumin (D) and both of them (E) resulted in $82.22 \%, 78.91 \%, 96.63 \%$ apoptosis respectively. The fluorescent image by confocal laser scanning in group B showed increase of the red fluorescence in the nucleus and cytoplasm of the squamous cell carcinoma cells indicating high proliferating cells while the fluorescent image of group C, D and E showed decrease of the red florescence in the nuclei of the squamous cell carcinoma cells indicating low proliferation.
\end{abstract}

CONCLUSIONS: Green tea and curcumin have a significant chemopreventive effect against oral carcinogenesis and the combination of both agents has a better effect.

KEYWORDS: Oral Squamous Cell Carcinoma, Chemoprevention, Green Tea, Curcumin.

1. Assistant lecturer Oral Pathology, Faculty of Dentistry, Alexandria University.

2. Professor of Oral Pathology, Faculty of Dentistry, Alexandria University.

3. Professor Histology and Cell Biology, Faculty of Medicine, Alexandria University

4. Assistant Professor Oral Pathology, Faculty of Dentistry, Alexandria University.

*Corresponding author:

E-mail: dr.mai.mahmoud@gmail.com

\section{INTRODUCTION}

Oral squamous cell carcinoma (OSCC) has the highest mortality rate among all carcinomas and is the most common head and neck cancer (1). The incidence of OSCC is between the ages of 45 and 75 years and is gradually increasing (2). The etiology of OSCC involves both intrinsic and extrinsic factors such as smoking, alcohol consumption and human papilloma virus infection being the main risk factors (3). Poor therapeutic response, recurrence and metastasis are commonly encountered despite considerable advances in surgery, radiotherapy and chemotherapy (4).

Attention has always been focused on understanding the molecular mechanisms of human oral carcinogenesis. Chemoprevention is a promising treatment strategy. Topical and systemic use of natural chemopreventive agents is an attractive alternative that decreases the toxic effects (5).

Several natural compounds and micronutrients (green tea extract, curcumin, resveratrol, broccoli sprout extract, soybean extracts, vitamin E, vitamin C, lyophilized black raspberries and pomegranate juice) have been under investigation for their adequacy in oral cancer chemoprevention $(6,7)$. These compounds contain high levels of polyphenols with anti-oxidant, anti-migratory, antiproliferative and anti-invasive effects on cancer cell properties and are proposed to restrain carcinogenesis through their action on downstream signaling pathways (8).

Tea is one of the most popular beverages consumed worldwide. Many studies have demonstrated that green tea, black tea and tea constituents have inhibitory effects on liver, small intestine, pancreas and bladder $(9,10)$. High levels of tea catechins in human saliva were detected after tea consumption suggesting that the oral cavity could be a good target to exert its chemopreventive effect against carcinogenesis (11).

Green tea (camellia sinensis) contains various cancer preventive catechins which are epigallocatechin gallate (EGCG), epigallocatechin (EGC) and epicatechin gallate 
(ECG). It was found that drinking over 10 cups (120 $\mathrm{mL} / \mathrm{cup}$ ) of green tea per day could prevent cancer recurrence in various organs in humans $(12,13)$. In 1987, the cancer preventive activity of EGCG was first reported (14), and since then, the significance of EGCG and green tea in cancer prevention and treatment has become widely recognized (15).

Curcumin, a natural polyphenol, is one of the most investigated biomolecules from mother nature. Its natural source, Curcuma longa or turmeric is used in Indian ayurvedic and siddha medicines and also in Chinese medicines since thousands of years. Turmeric is a perennial plant of the ginger family which is cultivated in tropical and subtropical regions of South Asia. India is one of the largest producers of turmeric (16). In Ayurveda, turmeric is used to treat diseases like arthritis, sprains, open wounds, acnes, stomach upset, flatulence, dysentery, ulcers, jaundice, skin and eye infections. Both turmeric and its active principle, curcumin, have been widely used as a spice, food preservative, coloring agent and an additive in cosmetic and drug preparations (17).

The different biological and pharmacological actions of curcumin e.g., anti-inflammatory, antioxidant, antiischemic, antibacterial, antifungal, and anticancer are due to different methoxy substitutions in the chemical structure of these compounds (18). Curcumin has also been shown to exert significant inhibitory growth effect on oral precancerous and carcinoma cell lines, and the effect is synergistic with EGCG, the most abundant polyphenol in tea (19).

The 7,12-dimethylbenz(a)anthracene (DMBA) is commonly utilized as a major carcinogen to develop tumors in the golden Syrian hamsters' buccal pouches (20). DMBA causes neoplasm by inducing severe inflammation and dysplasia in the buccal pouches as well as by causing extensive oxidative damage to DNA (21).

Accumulated evidences pointed out histological, morphological, biochemical and molecular similarities between DMBA induced oral tumors and human oral tumors (22). Carcinoma is usually preceded by a sequence of hyperplasia-papilloma and dysplasia-carcinoma similar to human leukoplakia. This experimental oral cancer model is therefore utilized as a preferred one to study the tumor preventive potential of natural products and their bioactive constituents (21).

Many natural cancer chemopreventive compounds are known to induce apoptosis. At the molecular level, dietary chemopreventive compounds can modulate a number of key elements of cell signal transduction pathways involved in the apoptotic process. Annexin V is a cellular protein which is commonly used to detect apoptotic cells by its ability to bind to phosphatidylserine, a marker of apoptosis when it is on the outer leaflet of the plasma membrane. The function of the protein is unknown; however, annexin A5 has been proposed to play a role in the inhibition of blood coagulation by competing for phosphatidylserine binding sites with prothrombin and also to inhibit the activity of phospholipase A1 (23).

The aim of the present work was to assess the chemopreventive effect of green tea and curcumin through induction of hamster buccal pouch carcinoma by using an apoptotic marker and to compare the chemopreventive effect of green tea, curcumin and both of them through induction of hamster buccal pouch carcinoma.

\section{MATERIALS AND METHODS}

The present study included 50 Syrian golden male hamsters (Five weeks old), weighting 80-129 grams were obtained from holding company for biological products and vaccines (VACSERA), Helwan, Cairo, Egypt. They were housed in show box cages, one per cage at the experimental animal unit in the Medical Technology Center of Medical Research Institute, Alexandria University. The experiment followed the guidelines for the care and use of experimental animals adopted by the Medical Research Institute. The green tea chemopreventive agent is prepared as solids which were made fresh (6 mg tea solids/ml) and were given to the hamsters as the sole source of drinking whereas the curcumin (10 mmol) was dissolved in $100 \mathrm{ml}$ paraffin oil and was applied topically on the left buccal pouch three times/ week in alternative days with the carcinogen. Animals were divided into 5 groups (10 each). The first group (A) was used as a normal control group from which normal buccal pouches were dissected. The second group (B) received the carcinogenic agent only and was considered as positive control group. The other three groups received green tea (C), curcumin (D) and combination of both (E), respectively. After 18 weeks from cancer induction and applying the chemopreventive agents, the left buccal pouch of each animal was examined for clinicopathological changes.

After the hamsters were sacrificed, the biopsy was divided into 2 pieces. Tumor cells isolated from primary tumors of the induced buccal SCC were incubated with Annexin V conjugated to FITC fluorochromes to assess early phase apoptosis using FACs (Fluorescent-activated cell sorter) caliber flow cytometry and cell sorter by quantitative flow cytometric analysis.

The second part of the biopsy taken from different animal groups was fixed in $10 \%$ buffered formalin solution and embedded in paraffin. Sections $4 \mu \mathrm{m}$ thick were mounted on glass slides stained with hematoxylin and eosin (H\&E) from all the test groups and were examined under light microscopy to confirm the induced carcinoma or dysplasia.

Proliferating cell nuclear antigen (PCNA) immunofluorescence was used to compare cellular proliferation rates among study and control groups. Examination was done by confocal laser scanning (CLS); Leica TSC SPE II/ DMi 8, unit of Advanced Microscopy, at CERMA.

\section{Statistical analysis}

All data were collected; tabulated and statistically analyzed using SPSS system (Statistical Package for Scientific Studies). ANOVA test was used to analyze the data between the study groups.

A (P) value less than 0.05 was considered significant. The values were given as a mean value \pm SD (standard deviation).

\section{RESULTS}

In the present work, a total of 50 male Syrian gold hamsters were included. After 18 weeks, the left buccal pouches were examined carefully for the presence or absence of any pathological changes. Clinical examination, histological finding, flow cytometry for apoptosis 
detection and immunofluorescence staining were evaluated.

\section{1-Clinical evaluation}

Group A (normal control) revealed normal pale pink color of the hamster buccal pouch (HBP) with neither pathological nor inflammatory changes. Group B (positive control) showed well developed oral exophytic lesions in all HBP (100\%). Seven hamsters exhibited red lesions (Figure 1A) and three hamsters showed evident red and white lesions. Group C revealed white patches in seven hamsters (70\%) (Figure 1B), while two hamsters (20\%) revealed small exophytic lesions. In only one hamster (10\%), no pathological changes were seen. Group D showed red patches in five hamsters (50\%) and 3 hamsters (30\%) revealed small exophytic lesions. No pathological changes were seen in the remaining two hamsters (20\%). Group E showed white patches in seven hamsters (70\%), while three hamsters (30\%) revealed only tiny red exophytic lesions.
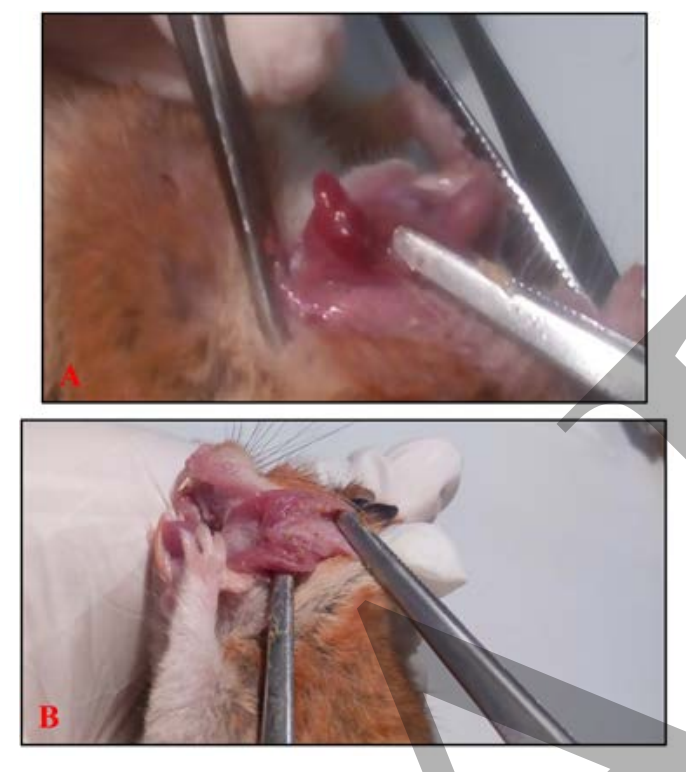

Figure (1): A- The hamster buccal pouch (HBP) showing a red exophytic mass (Group B).

B- The hamster buccal pouch (HBP) showing areas of white patches (Group C).

\section{2-Histological findings}

In all examined sections in group $\mathrm{A}$, the lining epithelium of HBP mucosa showed flat keratinized stratified squamous epithelium without rete ridges, consisting of 4 distinct layers which are the basal cell layer, the spinous cell layer, thin granular cell layer and keratinous layer. The subepithelial connective tissue consisted of dense fibrous tissue with absence of glands or any accessory structures. In group $\mathrm{B}$, four HBP revealed well differentiated oral SCC where malignant epithelial cells formed keratin and epithelial pearls (Figure 2A). The other six hamsters showed moderately differentiated oral SCC where malignant epithelial cells formed epithelial nests and few keratin pearls. Malignant criteria such as pleomorphism, hyperchromatism and abnormal mitotic figures were detected.

In group $\mathrm{C}$, dysplastic changes in the epithelial layer of seven hamsters were detected (Figure 2B) while two hamsters showed well differentiated SCC. Only one showed no pathological changes in the lining epithelium.
Histological examination of HBP sections in group D revealed moderate to severe epithelial dysplasia in five hamsters (Figure 3A) while three hamsters showed evident invasive carcinoma. No pathological changes in the lining epithelium of the remaining two hamsters were seen. In group E, moderate to severe epithelial dysplasia with areas of top to bottom changes or carcinoma in situ were seen in seven hamsters (Figure $3 \mathrm{~B}$ ) while three hamsters showed well differentiated SCC.
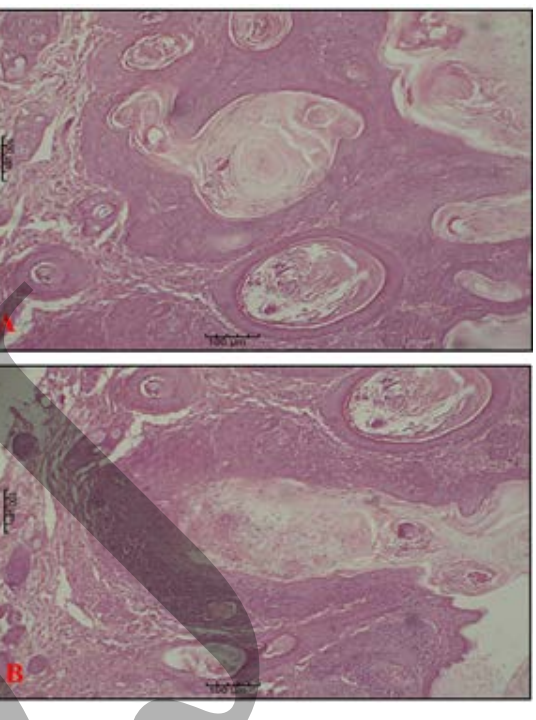

Figure (2): A- A photomicrograph showing well differentiated SCC with evident large epithelial pearl (Group B) (H\&E X100).

B- A photomicrograph showing severe dysplastic changes with invasive well differentiated SCC (Group C) (H\&E X100).
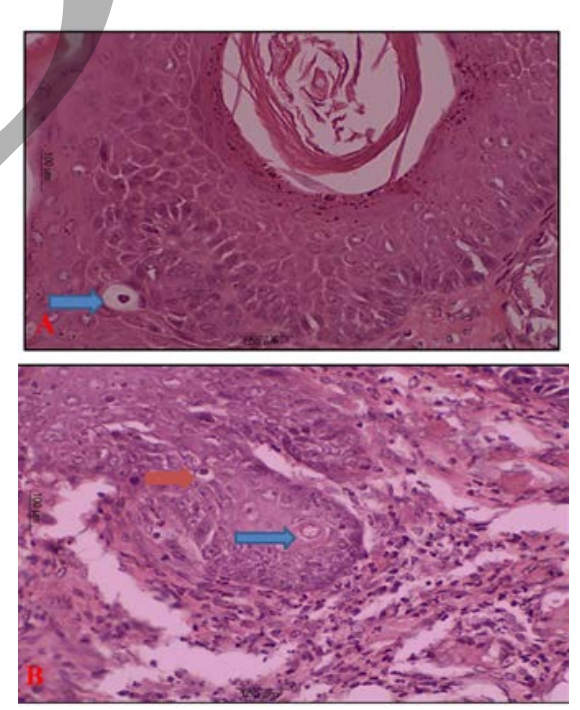

Figure (3): A- A photomicrograph showing moderate epithelial dysplasia with evident apoptotic body (blue arrow) (Group D) (H\&E X400).

B- A photomicrograph showing carcinoma in situ with abnormal keratinization (blue arrow) and apoptotic body (red arrow) (Group E) (H\&E X400).

\section{3-Detection of apoptosis by flow cytometry}

The flow cytometry profiles were displayed as a fourquadrant scatterplot. The profile graph, presented the Annexin V FITC parameter along the $\mathrm{X}$-axis and the PI (Propidium iodide) parameter along the $\mathrm{Y}$-axis. The four quadrants of the scatterplot presented, in a clockwise direction starting from the upper left quadrant: the population of necrosed cells, cells in late apoptosis, cells in early apoptosis, and the living cells, respectively. Of these 
four kinds of cell modes, early and late apoptosis were calculated among the cell population.

In the untreated cells (normal control), $1.72 \%$ of the cells underwent apoptosis ( $0.81 \%$ early apoptosis, $0.91 \%$ late apoptosis) while the cells of positive control group resulted in $11.57 \%$ apoptosis (3.59\% early apoptosis, $7.98 \%$ late apoptosis) and only $8.16 \%$ necrosis. In the study groups, treatment of the cells with green tea resulted in $82.22 \%$ apoptosis (48.86\% early apoptosis, $33.36 \%$ late apoptosis) and $0.55 \%$ necrosis while treatment of cells with curcumin resulted in $78.91 \%$ apoptosis (4.25\%early apoptosis, $74.66 \%$ late apoptosis) and $5.87 \%$ necrosis. Cells treated with both green tea and curcumin resulted in $96.63 \%$ apoptosis $(14.70 \%$ early apoptosis, $81.93 \%$ late apoptosis) and $0.20 \%$ necrosis (Figure 4, Table 1).
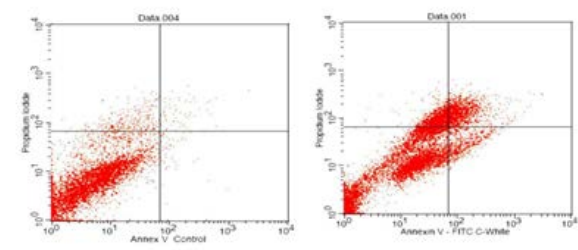

$c$

D
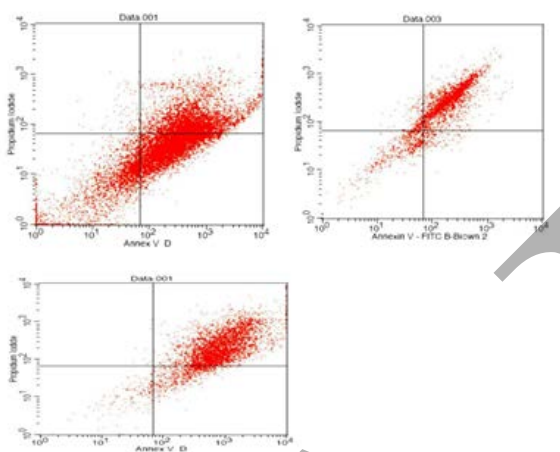

E

Figure (4): Flow Cytometry Scatter Plots for Annexin V-FITC and PI Staining to Evaluate Apoptosis in the Different Groups. A) Normal control. B) Positive control. C) Cells treated with green tea. D) Cells treated with curcumin. E) Cells treated with both green tea and curcumin. The cells were stained with Alexa Fluor 488 annexin V and PI for flow cytometry analysis. In each panel the lower left quadrant shows cells which are negative for both PI and Annexin V-FITC (living cells). Upper left quadrant shows only PI positive cells (necrotic). the lower right quadrant shows Annexin positive cells (early apoptotic cells) and the upper right quadrant shows Annexin and PI positive cells (late apoptosis cells).

Table (1): Summary of the Annexin V-FITC Apoptosis Assay Results.

\begin{tabular}{|c|c|c|c|c|c|}
\hline & $\begin{array}{c}\text { Normal } \\
\text { control }\end{array}$ & $\begin{array}{c}\text { Positive } \\
\text { control }\end{array}$ & $\begin{array}{c}\text { Green } \\
\text { tea }\end{array}$ & $\begin{array}{c}\text { Curcum } \\
\text { in }\end{array}$ & $\begin{array}{c}\text { Green } \\
\text { tea and } \\
\text { curcumi } \\
\text { n }\end{array}$ \\
\hline Living cells & $94.02 \%$ & $80.28 \%$ & $17.22 \%$ & $15.21 \%$ & $3.17 \%$ \\
\hline $\begin{array}{c}\text { Necrotic } \\
\text { cells }\end{array}$ & $4.26 \%$ & $8.16 \%$ & $0.55 \%$ & $5.87 \%$ & $0.20 \%$ \\
\hline $\begin{array}{c}\text { Early } \\
\text { apoptosis }\end{array}$ & $0.81 \%$ & $3.59 \%$ & $48.86 \%$ & $4.25 \%$ & $14.70 \%$ \\
\hline $\begin{array}{c}\text { Late } \\
\text { apoptosis }\end{array}$ & $0.91 \%$ & $7.98 \%$ & $33.36 \%$ & $74.66 \%$ & $81.93 \%$ \\
\hline $\begin{array}{c}\text { Apoptosis } \\
\text { (total) }\end{array}$ & $1.72 \%$ & $11.57 \%$ & $82.22 \%$ & $78.91 \%$ & $96.63 \%$ \\
\hline
\end{tabular}

\section{4-Immunofluoresence detection by confocal laser scanning using PCNA}

The DIC (Differential Interference Contrast) mode demonstrated the outline of the cells in the control and study groups. The fluorescent images labeled for the detection of PCNA in cancer cells indicated cell proliferation.

The DIC mode of group A revealed the surface epithelium and the underlying highly vascular connective tissue with no evidence of tumor cells while group $B$ revealed nests of SCC invading the underlying connective tissue. The cells were pleomorphic in shape with extending irregular cytoplasmic processes. The DIC mode for group C, D and E showed nests of SCC invading the underlying connective tissue with variable sizes.

The fluorescent image of group A showed the DNA of the cells as blue fluorescence with no red fluorescence indicating no proliferation in the normal control group while group B showed increase of the red fluorescence in the nucleus and cytoplasm of the squamous cell carcinoma cells indicating highly proliferating cells (Figure 5A, 5B).

The fluorescent image of group C, D and E showed decrease of the red fluorescence in the nuclei of the squamous cell carcinoma cells indicating low cellular proliferation (Figure 6A, 6B).

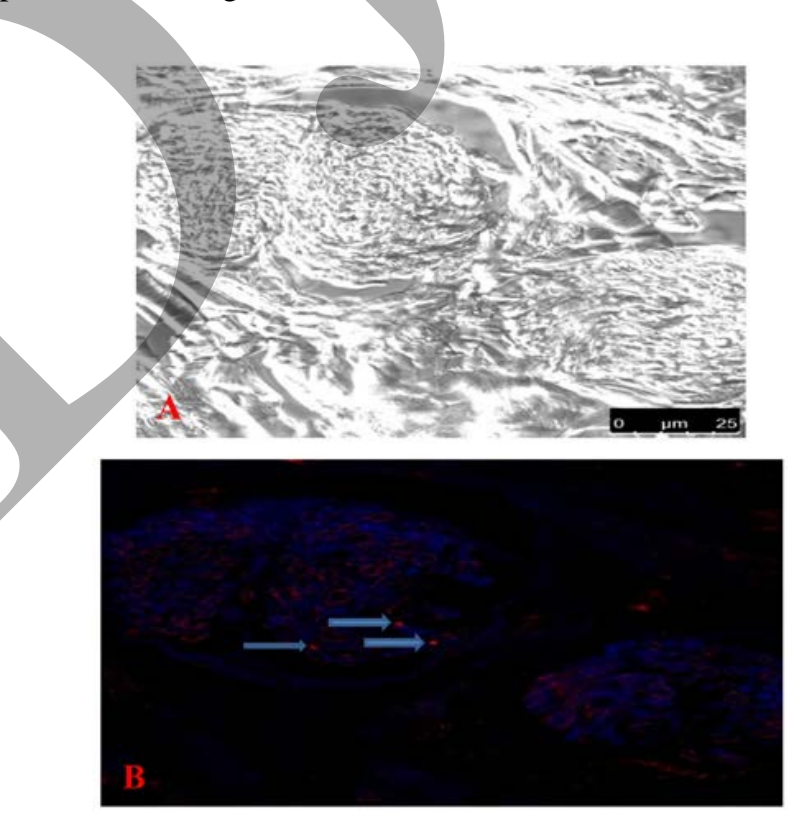

Figure (5): A- Confocal Laser Scanning Photomicrograph showing nests of SCC invading the underlying connective tissue by The Phase Contrast Mode (DIC) (Group B).

B- Confocal Laser Scanning Photomicrograph showing red florescence in the nucleus of the SCC cells (blue arrows) (Group B). 


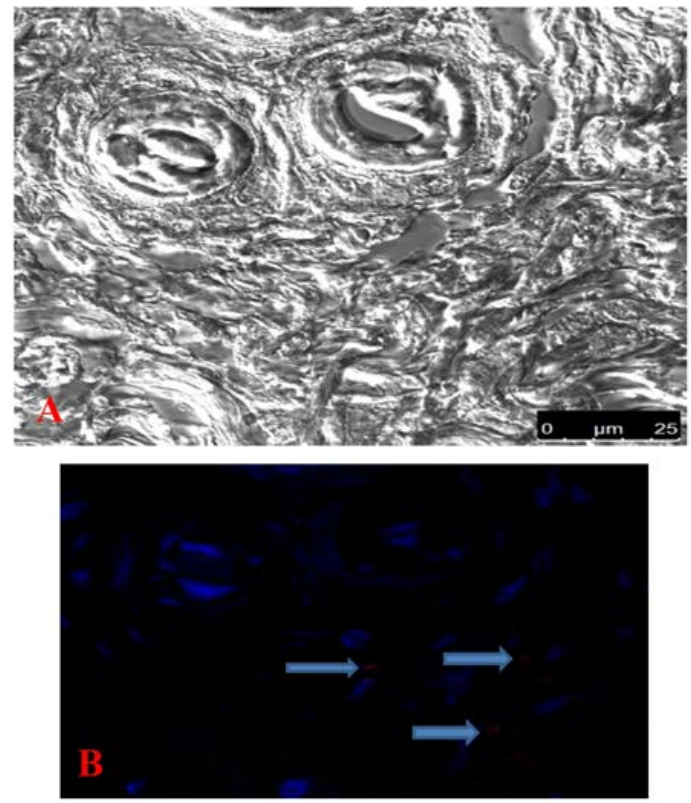

Figure (6): A- Confocal Laser Scanning Photomicrograph showing nests of SCC with depressed area of the center revealed keratin by The Phase Contrast Mode (DIC) (Group E).

B- Confocal Laser Scanning Photomicrograph showing red florescence in the nuclei of the SCC (blue arrows) (Group E).

\section{DISCUSSION}

Oral squamous cell carcinoma is a type of malignancy that develops from the epithelial layer of the oral cavity. It is a major cause of morbidity and mortality with a poor 5-year survival rate despite of the developments made in the therapeutic approach over the past few decades (24).

As a result of failure of conventional therapeutic approach in some difficult cases, the chemoprevention has evolved as a promising strategy to inhibit, suppress or control the incidence of carcinogenesis by using specific natural and synthetic agents (25). Green tea and curcumin are considered promising natural chemopreventive agents against oral carcinogenesis as they contain high levels of polyphenols. Both green tea and curcumin are known to induce apoptosis by regulating the transduction pathways involved in the apoptotic process (23).

In the current study, hamsters in the second group (B) that were subjected to topical application of DMBA alone, all showed well visible tumors in their buccal pouches. The results are in agreement with Manoharan et al., (2) and Selvasundaram et al., (26) mentioned that a 100\% tumor incidence was found in all the hamsters receiving DMBA carcinogen application included in their studies, thus suggesting DMBA to be considered a powerful tumor inducer. Contrastingly, in the study conducted by $\mathrm{Li}$ et al., (19) Only $77 \%$ of the hamsters developed buccal pouch tumors, and that could be attributed to the different animal species.

When it comes to evaluating the inhibitory effect of green tea on carcinogenesis, the hamsters that were given green tea as the sole source of drinking concomitant with DMBA application showed a decrease in the incidence of tumors developed when compared with the incidence in hamsters that were subjected to DMBA only, this was in agreement with Li et al., (19) and Yan et al., (27) and with many studies $(28,29)$ evaluating the inhibitory effect of green tea against carcinogenesis in rodents which were chemically induced to produce cancer in many organs.
As for the group of hamsters in this present study that had their buccal pouches painted with curcumin concomitant with DMBA application; they showed a reduction in tumor development when compared to the hamsters subjected to carcinogen application without receiving any chemopreventive agent. Different studies revealed that there are different methods for curcumin application which may be either orally, injection or topical application. Such results are supported by Li et al., (19) who reported decrease in the incidence of oral cancer in HBP induced by DMBA application. Also, Bimonte et al., $(30,31)$ assessed the antitumor effect of curcumin against breast and pancreatic cancer in mouse model and showed decrease in tumor formation.

Moreover, LoTempio et al., (32) found that the effects of curcumin in mice seemed to result from the amount of drug available at the tumor site. However, Huang et al., (33) reviewed that topical treatment of curcumin inhibits Benzo[a]pyrene and DMBA initiation, TPA-induced tumor promotion, and epidermal cell proliferation in mice.

In the current work, the hamsters which were painted with DMBA concomitant with both curcumin application and green tea as a sole source of drinking showed decrease of tumor incidence compared to the hamsters receiving DMBA application concomitant with green tea or curcumin only. The obtained results were in accordance with $\mathrm{Li}$ et al., who found decrease of tumor incidence, multiplicity and volume when using both agents together in HBP carcinoma induced by DMBA (19). This could be attributed to the effect of green tea on enhancing the intake of curcumin and its low bioavailability. Another study was performed on mice revealed that the combination of green tea and curcumin was effective in decreasing breast cancer (34).

Chemopreventive agents are known to induce apoptosis and decrease cell proliferation. In this work, flow cytometry assay using annexin V/ FITC was applied to assess the effect of green tea and curcumin on the induction of programmed cell death (apoptosis) in hamster buccal pouch carcinoma cells. Additionally, PCNA immunofluorescence which was done using confocal laser scanning evaluating cell proliferation to compare the chemopreventive effect of green tea and curcumin then both of them together on induced hamster buccal pouch carcinomas.

Treatment of the cells with green tea resulted in 82.22 $\%$ apoptosis while the cells of positive control resulted in $11.57 \%$ apoptosis. By confocal laser scanning, the fluorescent image showed significant decrease of the red fluorescence in the nuclei of the SCC cells indicating low proliferation and the statistical analysis confirmed that it is statistically significant $(\mathrm{p}<0.001)$ between the group of hamsters taking green tea with DMBA and the positive control group.

Studies conducted by Xiao et al., (35) and Yuan et al., (36) showed that green tea may be most effective in postinitiation, via the inhibition of cell proliferation in the rats colon hence suppression of early lesions. It significantly decreased cyclin D1 levels in the colonic mucosa of rats.

As for the group of hamsters where buccal pouches were painted with curcumin concomitant with DMBA, treatment of cells with curcumin resulted in 78.91\% apoptosis. As well as the fluorescent image by confocal laser scanning revealed minimal red fluorescence in the 
nuclei of the SCC cells which indicated decrease of cell proliferation. It is statistically significant $(\mathrm{p}<0.001)$ between this group and the positive control group according to cell proliferation.

Our results were in agreement with the results of Brandon (37) who demonstrated the inhibitory effect of $0.6 \%$ curcumin on cellular proliferation and p53 accumulation and induction of apoptosis in buccal pouch of hamsters, that were treated with Benzo[a]pyrene carcinogen. Also Patel et al., (38) found that another important factor determining the fate of the cell towards death or survival is the ratio of $\mathrm{Bax} / \mathrm{Bcl} 2$. Moreover, Garg et al., (39) found that PCNA is over expressed during DMBA-induced HBP carcinogenesis and highlighted that throughout the course of evaluation curcumin significantly decreased the DMBA-induced PCNA levels.

On referring to the results obtained from the flow cytometry for the group of hamsters that received both green tea and curcumin concomitant with DMBA application, the cells resulted in $96.63 \%$ apoptosis. Also this result was supported by the confocal laser scanning as the fluorescent image showed decrease of the red fluorescence in the nuclei of the SCC cells indicating low proliferation. By statistical analysis, a statistical difference $(\mathrm{p}<0.001)$ was found between this group and the positive control group.

In agreement with the previous results, Zhou et al., (40) concluded that either green tea or curcumin was a powerful inhibitor of cell cycle related proteins and cell cycle kinases. Combination of these two compounds may simultaneously target multiple cell cycle related pathways. They found that cyclin B1 and cyclin D1 were inhibited by green tea combined with curcumin, resulting in a significant $\mathrm{G} 1$ and S/G2 phases arrest.

Brandon (37) also found that these compounds may inhibit cell proliferation and/or prevent initiation by preventing DNA damage by blocking carcinogen metabolism and DNA adduct formation, or preventing genetic mutations.

\section{CONCLUSION}

Green tea and curcumin have a significant chemopreventive effect against oral squamous cell carcinoma as single agents from the aspect of their apoptotic and anti-proliferative action on tumor cells. Their anti-cancer potential is considered as a combination rather than individual treatments to prevent progression of oral SCC.

\section{CONFLICT OF INTEREST}

The authors declare that they have no conflicts of interest.

\section{REFERENCES}

1. Kwon MJ. Emerging Roles of Claudins in Human Cancer. Int J Mol Sci. 2013;14:18148-80.

2. Manimaran A, Buddhan R, Manoharan S. Emodin downregulates cell proliferation markers during DMBA induced oral carcinogenesis in golden Syrian hamsters. Afr J Tradit Complement Altern Med. 2017;14:83-91.

3. Qiao B, Cai JH, King-Yin Lam A, He BX. MicroRNA542-3p inhibits oral squamous cell carcinoma progression by inhibiting ILK/TGF-Î²1/Smad2/3 signaling. Oncotarget. 2017;8:70761-76.

4. Blatt S, Krüger M, Ziebart T, Sagheb K, Schiegnitz E, Goetze E, et al. Biomarkers in diagnosis and therapy of oral squamous cell carcinoma: a review of the literature. J Craniomaxillofac Surg. 2017;45:722-30.

5. Bodhade AS, Dive AM. Chemoprevention of premalignant and malignant lesions of oral cavity: Recent trends. Eur J Dent.2013;7:246-50.

6. Knobloch TJ, Uhrig LK, Pearl DK, Casto BC, Warner BM, Clinton SK, et al. Suppression of Proinflammatory and Prosurvival Biomarkers in Oral Cancer Patients Consuming a Black Raspberry Phytochemical-Rich Troche. Cancer Prev Res. 2016;9:159-71.

7. Warner BM, Casto BC, Knobloch TJ, Accurso BT, Weghorst CM. Chemoprevention of oral cancer by topical application of black raspberries on high at-risk mucosa. Oral Surg Oral Med Oral Pathol Oral Radiol. 2014;118:674-83.

8. Saba NF, Haigentz M Jr, Vermorken JB, Strojan P, Bossi $\mathrm{P}$, Rinaldo A, et al. Prevention of head and neck squamous cell carcinoma: Removing the "chemo" from “chemoprevention”. Oral Oncol. 2015;51:112-8.

9. Singh A, Tripathi P. Potential of Natural Products for the Prevention of Oral Cancer. In: Anticancer Plants: Natural Products and Biotechnological Implements. Springer Nature Singapore Pte Ltd; 2018. p. 41-66.

10. Ohishi T, Goto S, Monira P, Isemura M, Nakamura Y. Anti-inflammatory action of green tea. . Antiinflamm Antialler Agents Med Chem. 2016;15:74-90.

11. Lee UL, Choi SW. The chemopreventive properties and therapeutic modulation of green tea polyphenols in oral squamous cell carcinoma. ISRN Oncol. 2011;2011: 403707.

12. Siemianowicz K, Likus W, Dorecka M, Wilk R, Dziubdziela W, Markowski J. Chemoprevention of Head and Neck Cancers: Does It Have Only One Face? Biomed Res Int. 2018;2018:9051854.

13. Ramshankar V, Krishnamurthy A. Chemoprevention of oral cancer: Green tea experience. J Nat Sci Biol Med. 2014;5:3-7.

14. Yoshizawa S, Horiuchi T, Fujiki H, Yoshida T, Okuda T, Sugimura T. Antitumor promoting activity of (-)epigallocatechin gallate, the main constituent of "Tannin" in green tea. Phytother Res. 1987;1:44-7.

15. Fujiki H, Imai K, Nakachi K, Shimizu M, Moriwaki H, Suganuma MJ. Challenging the effectiveness of green tea in primary and tertiary cancer prevention. Cancer Res Clin Oncol. 2012;138:1259-70.

16. Aggarwal BB, Sung B. Pharmacological basis for the role of curcumin in chronic diseases: an age-old spice with modern targets. Trends Pharmacol Sci. 2009;30:85-94.

17. Esatbeyoglu T, Huebbe P, Ernst IM, Chin D, Wagner AE, Rimbach G. Curcumin-from molecule to biological function. Angew Chem Int Ed Engl. 2012;51:5308-32.

18. Nabavi FS, Daglia M, Moghaddam HA, Habtemariam S, Nabavi MS. Curcumin and liver disease: from chemistry to medicine. Compr Rev Food Sci Food Saf. 2014;13:62-77. 
19.Li N, Chen X, Liao J, Yang G, Wang S, Josephson Y, et al. Inhibition of 7,12-dimethylbenz(a)anthracene (DMBA)induced oral carcinogenesis in hamsters by tea and curcumin. Carcinogenesis. 2002;23:1307-13.

20. Vidya Priyadarsini R, Senthil Murugan R, Nagini S. Aberrant activation of $\mathrm{Wnt} / \beta$ - catenin signalling pathway contributes to the sequential progression of DMBAinduced HBP carcinomas. Oral Oncol. 2012;48:33-9.

21. Karthikeyan S, Srinivasan R, Wani SA, Manoharan S. Chemopreventive potential of chrysin in 7, 12dimethylbenz (a) anthracene-induced hamster buccal pouch carcinogenesis. Int J Nutr Pharmacol Neurol Dis. 2013;3:46-53.

22. Nagini S. Of humans and hamsters: the hamster buccal pouch carcinogenesis model as a paradigm for oral oncogenesis and chemoprevention. Anticancer Agents Med Chem. 2009;9:843-52.

23. Tavakoli MB, Kheirollahi M, Kiani A, Kazemi M, Javanmard SH, Mohebat L. Annexin V FITC conjugated as a radiation toxicity indicator in lymphocytes following radiation overexposure in radiotherapy programs. Adv Biomed Res. 2015;4:119.

24. Rundhaug JE, Fischer SM. Molecular mechanisms mouse skin tumor promotion. Cancers. 2010;2:436-82.

25. Ekor M. The growing use of herbal medicines: issues relating to adverse reactions and challenges in monitoring safety. Front Pharmacol. 2014;4:177.

26. Selvasundaram R, Manoharan S, Buddhan R, Neelakandan M, Naidu RM. Chemopreventive potential of esculetin in 7 , 12-dimethylbenz (a) anthracene-induced hamster buccal pouch carcinogenesis. Mol Cell Biochem. 2018;448:145-53.

27. Yan LJ, Chen F, Liu DM, Huang JF, Liu FP, Wu JF, et al. Tea, coffee intakes and risk of oral squamous cell carcinoma: A case-control study. Zhonghua Liu Xing Bing Xue Za Zhi. 2016;37:1531-5.

28.Wang ZY, Wang LD, Lee MR, Ho CT, Huang MT, Conney $\mathrm{AH}$, et al. Inhibition of Nnitrosomethylbenzylamine-induced esophageal carcinogenesis in rats by green tea and black tea. Carcinogenesis. 1995;16:2143-8.

29. Luo SQ, Liu XZ, Wang CJ. Inhibitory effect of green tea extract on the carcinogenesis induced by asbestos plus benzo[a]pyrene in rat. Biomed Environ Sci. 1995;8:54-8.

30. Bimonte S, Barbieri A, Palma G, Rea D, Luciano A, D'Aiuto $\mathrm{M}$, et al. Dissecting the role of curcumin in tumour growth and angiogenesis in mouse model of human breast cancer. Biomed Res Int. 2015;2015:878134.
31. Bimonte S, Barbieri A, Palma G, Luciano A, Rea D, Arra C. Curcumin inhibits tumor growth and angiogenesis in an orthotopic mouse model of human pancreatic cancer. Biomed Res Int. 2013;2013:810423.

32. LoTempio MM, Veena MS, Steele HL, Ramamurthy B, Ramalingam TS, Cohen AN, et al. Curcumin suppresses growth of head and neck squamous cell carcinoma. Clin Cancer Res. 2005;11:6994-7002.

33. Huang MT, Newmark HL, Frenkel K. Inhibitory effects of curcumin on tumorigenesis in mice. J Cell Biochem Suppl. 1997;27:26-34.

34. Somers-Edgar TJ, Scandlyn MJ, Stuart EC, Le Nedelec MJ, Valentine SP, Rosengren RJ. The combination of epigallocatechin gallate and curcumin suppresses ER alpha-breast cancer cell growth in vitro and in vivo. Int J Cancer. 2008;122:1966-71.

35. Xiao H, Hao X, Simi B, Ju J, Jiang H, Reddy BS, et al. Green tea polyphenols inhibit colorectal aberrant crypt foci (ACF) formation and prevent oncogenic changes in dysplastic ACF in azoxymethane-treated F344 rats. Carcinogenesis. 2008;29:113-9.

36. Yuan JH, Li YQ, Yang XY. Protective effects of epigallocatechin gallate on colon preneoplastic lesions induced by 2-amino-3-methylimidazo[4, 5- f]quinoline in mice. Mol Med. 2008;14:590-8.

37. Brandon JL. Chemopreventive effects of curcumin and green tea on B [a] P-induced carcinogenesis in the hamster cheek pouch. Ph.D. Thesis. Texas A\&M University. 2005.

38. Patel R, Ingle A, Maru GB. Polymeric black tea polyphenols inhibit 1, 2- dimethylhydrazine induced colorectal carcinogenesis by inhibiting cell proliferation via Wnt/beta-catenin pathway. Toxicol Appl Pharmacol. 2008;227:136-46.

39. Garg R, Ingle A, Maru G. Dietary turmeric modulates DMBA-induced p21ras, MAP kinases and AP-1/NFkappaB pathway to alter cellular responses during hamster buccal pouch carcinogenesis. Toxicol Appl Pharmacol. 2008;232:428-39.

40.Zhou DH, Wang X, Yang M, Shi X, Huang W, Feng Q. Combination of low concentration of (-)-epigallocatechin gallate (EGCG) and curcumin strongly suppresses the growth of non-small cell lung cancer in vitro and in vivo through causing cell cycle arrest. I Int J Mol Sci. 2013;14:12023-36. 